\title{
Prevalence, health and social hazards, and attitude toward early marriage in ever-married women, Sohag, Upper Egypt
}

\author{
Original \\ Article \\ Ahmed F. Hamed and Fouad M.A. Yousef \\ Public Health and Community Medicine Department, Faculty of Medicine, Sohag University, \\ Sohag, Egypt
}

\begin{abstract}
Background: Early marriage is associated with many social, physical, and health problems and it is common in many developing countries including Egypt. Many factors affect the decision of the timing of marriage. In this study, we aim to estimate the prevalence, social and health hazards and to identify the attitudes and factors that affect attitudes toward early marriage.

Patients and Methods: This cross-sectional study was done in Sohag, Upper Egypt. Random samples of ever-married women aged 20-60 years were taken from six districts. A questionnaire was designed to collect the data.

Results: The prevalence of early marriage is about $60 \%$. The associated self-reported health and social hazards included: anemia (18\%), hemorrhage (27.5\%), uterine prolapse (37\%), preterm (36\%), low birth weight (31\%), delayed immunization of infants (94\%), separation from the husband (17\%), and discontinuation of education (23\%). About $42 \%$ of the studied population supported early marriage. Reasons for supporting include: to prevent premarital promiscuity $(35 \%)$ and difficulty to get married later (28\%). Reasons for not supporting include: being harmful to mothers (26\%), difficulty in childcare, and discontinuation of education (18\% each). Final models of factors significantly affecting women's attitudes indicated that the factors for not supporting early marriage were: attaining higher education and believing that early marriage is due to ignorance, is more common among relatives, and causes health or social problems.

Conclusion: Early marriage is still very common in Sohag. Including the hazards of early marriage in the curriculum of preparatory and secondary schools as well as encouraging girls to complete their education up to the university stage will help in decreasing this problem.
\end{abstract}

Received: 5 October 2017, Accepted: 19 February 2018

Key Words: Attitude, child marriage and Egypt, early marriage, prevalence.

Corresponding Author: Fouad M.A. Yousef, Ph.D, Department of Community Medicine and Public Health, Faculty of Medicine, Sohag University, Sohag, Egypt Tel.: +20 127760 1847, E-mail: fouad3s@yahoo.com

Journal of the Egyptian Public Health Association, ISSN: 0013-2446, Vol. 92, No.4

\section{INTRODUCTION}

The age at first marriage is varying from one area to another in the world. However, there are many women married before 18 years in developing countries [1]. Marriage before this age is called 'child' or more commonly 'early marriage.' Egypt, one of the developing countries, suffers from this problem with one in six women still marrying early [2]. Egyptian demographic and health survey (EDHS) [3] showed that the early marriage prevalence ranged from $17 \%$ in women aged $20-24$ years to $33 \%$ in women aged $45-49$ years with a total prevalence of $23.8 \%$ among women aged from 20 to 49 years.

Early marriage is associated with many social, physical, and health problems such as discontinuation of education, depression, anxiety, divorce, anemia, osteoporosis, and cervical cancers [4-9]. Women married before 18 years are also more exposed to physical and sexual violence than those married after 18 years [10]. Early childbearing increases the risk of morbidity and mortality for mothers and infants $[1,6,11]$. Early marriage also prolongs the childbearing period which contribute to increased fertility and population problems in Egypt. In addition, infants born to early married women were have a high risk of being preterm or have low birth weight (LBW) [11]. In addition, infant mortality was higher in women less than 20 years compared with other women [11].

Many factors affect the decision of marriage timing [9]. In this study, we aimed to estimate the prevalence of early marriage in Sohag, Upper Egypt and its related social and health hazards. In addition, women's attitude toward early marriage and the factors affecting their attitudes were investigated.

\section{PATIENTS AND METHODS}

This is a cross-sectional study. The study was carried out during 2017n Sohag, one of the Upper Egypt governorates. This study included a sample of ever-married women aged 20-60 years from six clusters. EPI info version 7 (Epi Info $^{\mathrm{TM}}$, Center for Surveillance, Epidemiology \& Laboratory Services (CSELS)) was used to calculate the sample size. With a $99 \%$ confidence interval, a design effect of 2 and a $23.8 \%$ prevalence of early marriage [3], the minimum estimated sample size was calculated at 786 women. 
Random samples were taken from six districts. These districts are Sohag, Tahta, Dar El-salam, El-Monshah, Sakolta, and Gohina. From each district two areas were taken, one representing rural areas and the other representing urban areas.

A questionnaire was designed after reading previous articles related to the participant. Pilot study was performed on 100 women to test the questionnaire and to make necessary changes. The questionnaire was used to collect data about demographic and social characteristics, age at first marriage, and social or health hazards related to early marriage. A direct question, about if they support or not early marriage, was asked to measure their attitude toward early marriage. This was followed by questions about the reasons for supporting or not supporting it.

\section{Statistical analysis}

Data were analyzed by Stata, version 12.1 (Stata Statistical Software, Release 12; StataCorp LP., College Station, Texas, USA). Univariate logistic regression was used to report odds ratio and 95 confidence intervals. Significant data were entered in multivariate analysis. Only final model with significant variable in multivariate analysis was kept and shown in the results. A significant level was set if the $\mathrm{P}$ value is less than 0.05 .

\section{RESULTS}

This study included 1064 ever-married women with a mean age of 35 years. Other sociodemographic characteristics are shown in Table 1.

Table 1 Sociodemographic characteristics of studied women, Sohag, Egypt, 2017

\begin{tabular}{lc}
\hline Variables & Summary statistics \\
\hline Age & $34.83 \pm 8.47$ \\
Mean \pm SD & $33(20-60)$ \\
Median (range) & \\
Age group [n (\%)] (years) & $398(37.41)$ \\
$<30$ & $403(37.88)$ \\
30 to $<40$ & $184(17.29)$ \\
40 to $<50$ & $79(7.42)$ \\
$\geq 50$ & \\
Residence [n (\%)] & $541(50.85)$ \\
Rural & $523(49.15)$ \\
Urban & \\
Religion [n (\%)] & $905(85.06)$ \\
Muslims & $159(14.94)$ \\
Christian & \\
Level of education [n $(\%)]$ & $577(54.23)$ \\
Less than secondary & $487(45.77)$ \\
Secondary or more & \\
Occupation [n (\%)] & \\
Not working for cash & \\
Working for cash & \\
\cline { 2 - 2 } & \\
\hline
\end{tabular}

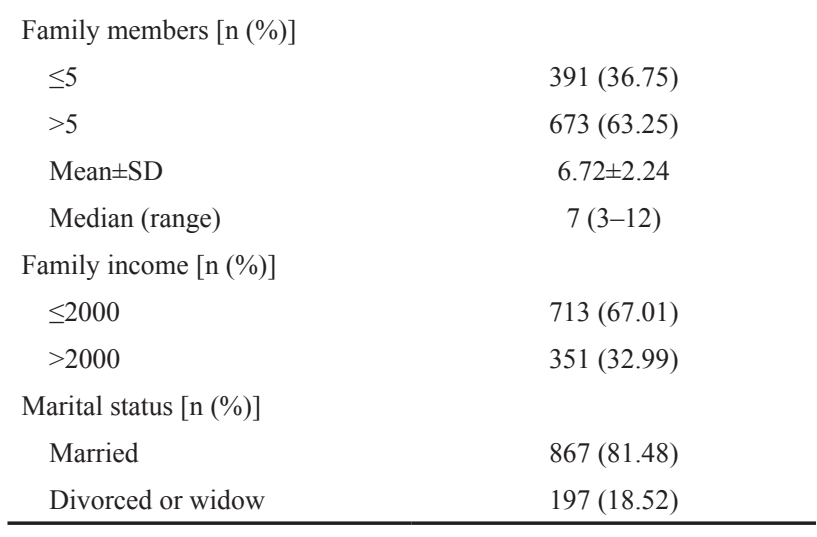

\section{Prevalence of early marriage}

Table 2 showed that the mean marriage age was $17.86 \pm 3.27$ years. It significantly decreased with age. It was $19.19 \pm 2.46$ in women aged up to 30 years, decreased gradually to reach $15.15 \pm 1.77$ in those aged more than 50 years $(\mathrm{P}<0.0001)$. The overall prevalence of early marriage was about $60 \%$. It was lower in women aged up to 30 years $(31 \%)$ compared with other age groups (about $77-78 \%, \mathrm{P}<0.0001)$. It was lower in urban than rural areas (37 vs. $82 \%, \mathrm{P}<0.0001$ ). Women with secondary or higher education had lower prevalence than those with less than secondary education ( 22 vs. $92 \%, \mathrm{P}<0.0001$ ). There was no relation between the prevalence of early marriage and religion $(0=0.68)$.

Table 2 Prevalence of early marriage by different characteristics of studied women, Sohag, Egypt, 2017

\begin{tabular}{lcc}
\hline Variables & $\begin{array}{c}\text { Prevalence of early marriage } \\
{[\mathrm{n}(\%)]}\end{array}$ & P value \\
\hline $\begin{array}{l}\text { All women } \\
\text { Age group (years) }\end{array}$ & $640(60.15)$ & \\
$<30$ & $125(31.41)$ & $<0.0001$ \\
30 to $<40$ & $311(77.17)$ & \\
40 to $<50$ & $142(77.17)$ & \\
$\geq 50$ & $62(78.48)$ & $<0.0001$ \\
Residence & & \\
Rural & $446(82.44)$ & \\
Urban & $194(37.09)$ & \\
Religion & & \\
Muslims & $542(59.64)$ & \\
Christian & $98(61.64)$ & \\
Level of education & & \\
Less than secondary & $533(92.37)$ & \\
Secondary or more & $107(21.97)$ & \\
\hline
\end{tabular}

\section{Hazards of early marriage}

Table 3 shows that women married before 18 years had health and social hazards and their infants also were affected. Health hazards included anemia (18\%), hemorrhage $(27.5 \%)$, uterine prolapse $(37 \%)$, toxemia of pregnancy $(8 \%)$, and gestational diabetes $(4 \%)$. The social problems reported were separation from the husband $(17 \%)$ 
and discontinuation of education (23\%). Mothers reported that many of them had preterm deliveries (36\%) and LBW infants (31\%). Immunization was delayed for most infants born to women younger than 18 years $(94 \%)$.

Table 3 Health and social hazards of early marriage reported by early married women, Sohag, Egypt, 2017

\begin{tabular}{lc}
\hline Hazards & $\mathrm{n}(\%)$ \\
\hline Health hazardsa & $450(70.31)$ \\
Anemia & $117(18.28)$ \\
Hemorrhage & $176(27.50)$ \\
Uterine prolapse & $237(37.03)$ \\
Toxemia of pregnancy & $50(7.81)$ \\
Gestational diabetes & $28(4.38)$ \\
Social problemsa & $181(28.28)$ \\
Separation from the husband & $106(16.56)$ \\
Discontinuation of education & $150(23.44)$ \\
Problem to infantsa & $599(93.59)$ \\
Preterm & $232(36.25)$ \\
Low birth weight & $202(31.56)$ \\
Delayed immunization & $599(93.59)$ \\
\hline The total does not sum up to $100 \%$ due to multiple responses.
\end{tabular}

\section{Attitude toward early marriage}

As shown in Table 4, about $42 \%$ of the studied populations supported early marriage. The reported reasons for supporting early marriage were to prevent premarital deviation (35\%), difficulty to get married later (28\%), less annoying to parents (13\%), less cost $(15 \%)$, and helping in childcare (8\%). Reasons for not supporting early marriage were harmful to mother $(26 \%)$, difficulty in childcare, discontinuation of education (18\% each), hinders mother's ambition (14\%), mother's death due to childbirth (12\%), and causing anemia for the mother $(9 \%)$.

Table 4 Attitude of studied women toward early marriage, Sohag, Egypt, 2017

\begin{tabular}{lc}
\hline Variables & $\mathrm{n}(\%)$ \\
\hline Attitude toward early marriage & $613(57.61)$ \\
Not supporting & $451(42.39)$ \\
Supporting & \\
Reasons for supporting early marriage & $160(35.48)$ \\
Prevent premarital promiscuity & $130(28.82)$ \\
Difficult to get married later & $58(12.86)$ \\
Less annoying to parents & $68(15.08)$ \\
Less cost & $35(7.76)$ \\
Helping in childcare & \\
Reasons for not supporting early marriage & $159(25.94)$ \\
Harmful to mothers & $111(18.10)$ \\
Difficulty in childcare & $74(12.07)$ \\
Mother's death due to childbirth & $56(9.06)$ \\
Causing anemia for the mother & $87(14.19)$ \\
Personal ambition prevention & $109(17.78)$ \\
Discontinuation of education & $17(2.77)$ \\
Others &
\end{tabular}

\section{Factor affecting attitude toward early marriage}

Table 5 shows univariate analysis of factors affecting the attitude toward early marriage. Women aged more than 40 years, those with family members more than five, and those believing that early marriage is due to poverty were supporting early marriage. On the other hand, women from urban residence, those with secondary or higher education, with a family income of more than 2000 pounds, with previous early marriage, believing that early marriage is due to tradition, ignorance, is common in relatives, causing health, social, or community problems were not supporting early marriage. However, factors such as religion, occupation, or marital status did not affect the attitude toward early marriage. In multivariate analysis, many factors became insignificantly related to the attitude to early marriage.

Table 6 shows the final models of factors significantly affecting women's attitudes. Only women with more than five family members were supporting early marriage (odds ratio: 2.79; confidence interval: 1.62-4.77). Higher education, believing early marriage is due to ignorance or is more among relatives, or is causing health or social problems were factors not supporting early marriage.

Table 6 Final multivariate regression model of factors supporting early marriage

\begin{tabular}{lcc}
\hline Variables & $\begin{array}{c}\text { Odds ratio } \\
(95 \% \text { confidence interval })\end{array}$ & P value \\
\hline Level of education & 1 & $<0.0001^{*}$ \\
Less than secondary & $0.35(0.21-0.58)$ & \\
Secondary or more & 1 & $<0.0001^{*}$ \\
Family members & $2.79(1.62-4.77)$ & \\
$\leq 5$ & 1 & $<0.0001^{*}$ \\
$>5$ & $0.12(0.08-0.18)$ & \\
Early marriage is due to ignorance & \\
No & 1 & \\
Yes & $0.29(0.19-0.43)$ & \\
Early marriage is more among relatives & \\
No & 1 & \\
Yes & $0.0006^{*}$ \\
Early marriage has health and social hazards for the family & \\
No & $0.35-0.84)$ & \\
Yes & & \\
* $<0.05$, statistically significant &
\end{tabular}


Table 5 Factors affecting attitude of studied women toward early marriage, Sohag, Egypt, 2017

\begin{tabular}{|c|c|c|c|c|c|}
\hline \multicolumn{6}{|c|}{ Attitude toward early marriage [n (\%)] } \\
\hline Variables & $\mathrm{n}(\%)$ & Not support $(\mathrm{N}=627)$ & Support $(\mathrm{N}=437)$ & Odds ratio ( $95 \%$ confidence interval) & $\mathrm{P}$ value \\
\hline \multicolumn{6}{|l|}{ Socioeconomic characteristics } \\
\hline \multicolumn{6}{|l|}{ Age group (years) } \\
\hline$\leq 40$ & $801(75.8)$ & $554(90.38)$ & $247(54.77)$ & 1 & $<0.0001 *$ \\
\hline$>40$ & $263(24.72)$ & $59(9.62)$ & $204(45.23)$ & $7.76(5.59-10.74)$ & \\
\hline \multicolumn{6}{|l|}{ Residence } \\
\hline Rural & $541(50.85)$ & $291(47.47)$ & $250(55.43)$ & 1 & $0.01 *$ \\
\hline Urban & $523(49.15)$ & $322(52.53)$ & $201(44.57)$ & $0.72(0.57-0.93)$ & \\
\hline \multicolumn{6}{|l|}{ Religion } \\
\hline Muslims & $905(85.06)$ & $521(84.99)$ & $384(85.14)$ & 1 & 0.95 \\
\hline Christian & $159(14.94)$ & $92(15.01)$ & $67(14.86)$ & $0.99(0.70-1.39)$ & \\
\hline \multicolumn{6}{|l|}{ Level of education } \\
\hline Less than secondary & $577(54.23)$ & $193(31.48)$ & $384(85.14)$ & 1 & $<0.0001^{*}$ \\
\hline Secondary or more & 487 (45.77) & $420(68.52)$ & $67(14.86)$ & $0.08(0.06-0.11)$ & \\
\hline \multicolumn{6}{|l|}{ Occupation } \\
\hline Not working for cash & $672(63.16)$ & $382(62.321)$ & $290(68.30)$ & 1 & 0.51 \\
\hline Working for cash & $392(36.84)$ & $231(37.68)$ & $161(35.70)$ & $0.91(0.71-1.18)$ & \\
\hline \multicolumn{6}{|l|}{ Family members } \\
\hline$\leq 5$ & $391(36.75)$ & $348(56.77)$ & $43(9.53)$ & 1 & $<0.0001 *$ \\
\hline$>5$ & $673(63.25)$ & $265(43.23)$ & $408(90.47)$ & $12.46(8.76-17.73)$ & \\
\hline \multicolumn{6}{|l|}{ Family income } \\
\hline$\leq 2000$ & $713(67.01)$ & $381(62.15)$ & $332(73.61)$ & 1 & $<0.0001 *$ \\
\hline$>2000$ & $351(32.99)$ & $232(37.85)$ & $119(26.39)$ & $0.59(0.45-0.77)$ & \\
\hline \multicolumn{6}{|l|}{ Marital status } \\
\hline Married & $867(81.48)$ & $502(81.89)$ & $365(80.93)$ & 1 & 0.69 \\
\hline Divorced or widow & $197(18.52)$ & $111(18.11)$ & $86(19.07)$ & $1.06(0.78-1.46)$ & \\
\hline \multicolumn{6}{|l|}{ Previous early marriage } \\
\hline \multicolumn{6}{|l|}{ Age of marriage (years) } \\
\hline$<18$ & $640(60.15)$ & $260(42.41)$ & $380(84.26)$ & 1 & $<0.0001^{*}$ \\
\hline$\geq 18$ & $424(39.85)$ & $353(57.59)$ & $71(15.74)$ & $0.14(0.10-0.19)$ & \\
\hline \multicolumn{6}{|l|}{ Beliefs and knowledge } \\
\hline \multicolumn{6}{|c|}{ Early marriage is due to poverty } \\
\hline No & 837 (78.67) & $521(84.99)$ & $316(70.07)$ & 1 & $<0.0001^{*}$ \\
\hline Yes & $227(21.33)$ & $92(15.01)$ & $135(29.93)$ & $2.41(1.79-3.26)$ & \\
\hline \multicolumn{6}{|c|}{ Early marriage is due to tradition } \\
\hline No & $785(73.78)$ & $400(65.25)$ & $385(85.37)$ & 1 & $<0.0001^{*}$ \\
\hline Yes & $279(26.22)$ & $213(34.75)$ & $66(14.63)$ & $0.32(0.24-0.44)$ & \\
\hline \multicolumn{6}{|c|}{ Early marriage is due to ignorance } \\
\hline No & $477(44.83)$ & $109(17.78)$ & $368(81.60)$ & 1 & $<0.0001 *$ \\
\hline Yes & $587(55.17)$ & $504(82.22)$ & $83(18.40)$ & $0.05(0.04-0.07)$ & \\
\hline \multicolumn{6}{|c|}{ Early marriage is more among relatives } \\
\hline No & $256(24.06)$ & $83(13.54)$ & $173(38.36)$ & 1 & $<0.0001^{*}$ \\
\hline Yes & $808(75.94)$ & $530(86.46)$ & $278(61.64)$ & $0.25(0.19-0.34)$ & \\
\hline \multicolumn{6}{|c|}{ Early marriage has health or social hazards for the family } \\
\hline No & $301(28.29)$ & $66(10.77)$ & $235(52.11)$ & 1 & $<0.0001^{*}$ \\
\hline Yes & $763(71.71)$ & $547(89.23)$ & $216(47.89)$ & $0.11(0.08-0.15)$ & \\
\hline \multicolumn{6}{|c|}{ Early marriage has a bad effect on community } \\
\hline No & $343(32.24)$ & $86(14.03)$ & $257(56.98)$ & 1 & $<0.0001^{*}$ \\
\hline Yes & $721(67.76)$ & $527(85.97)$ & $194(43.02)$ & $0.12(0.09-0.17)$ & \\
\hline
\end{tabular}




\section{DISCUSSION}

Early marriage before the age of 18 years is shown to have many drawbacks on the health of mothers and their children [12]. It is prohibited in many countries [12] including Egypt [3]. EDHS [3] showed that age at first marriage decreases with age, with a prevalence rate of early marriage of $23.8 \%$ for all women from age 20 to 49 years. In this study, although the prevalence rate of early marriage dropped from $78 \%$ in older groups to $31 \%$ in women aged less than 30 years; the prevalence was $60 \%$ for all women. Many factors could be related to the reported high prevalence in this study. For the overall prevalence, we included women aged up to 60 years and the prevalence increases in proportion to the increase in women's age. Early marriage rate was also high in many developing countries, for example, including Bangladesh (65\%) [13], Yemen (48.4\%) [14], South Asia (48\%), and Africa (42\%) [15].

In this study, the prevalence was lower in urban than in rural areas. This is in contrast with data from EDHS [3] that showed that the age at marriage was 4 years earlier in rural Upper Egypt than urban governorates. High early marriage prevalence in rural areas was reported in many studies from different countries [11,16,17]. In Egypt, early marriage is associated with lower wealth, lower education levels, and higher labor force participation that are more common in rural areas [2].

Previous studies [13,18-21] reported that female education is an important determinant of early marriage. Education has an important role in delaying the time of marriage. It also gives women new ideas and help in controlling their decision. Education helps women to improve their career and to wait for a better match [22]. The present study showed that women with secondary or higher education had lower prevalence than those with less than secondary education. This indicates the importance of female education in reducing early marriage.

A report from UNICEF showed that being a member of majority or minority religious group may or may not affect marriage before 18 years [15]. Our study reported no relation between the prevalence of early marriage and religion.

Many social, physical, and health problems like discontinuation from education, divorce, anemia, osteoporosis, cervical cancers, physical and social violence, increased morbidity and mortality for both mother and child including preterm and LBW were reported in previous studies [1,4-11]. Our study also showed that women who were married early reported that they suffered from many health problems mostly uterine prolapse (37\%), hemorrhage $(27.5 \%)$, and anemia (18\%). This study also found that about one-fifth early married women suffered from social problems such as separation from the husband and discontinuation of education. We also found that about one-third of infants born to early married women were preterm and/or of LBW and for most of them (94\%) their immunization was delayed.

Our study has shown that $42 \%$ of the studied population still supported early marriage. A higher proportion of women in our study supports early marriage than that from Bangladesh [13]. This is because our study included all women till the age of 60 years and not just adolescents.

Our study showed that the reported reasons for supporting early marriage were to prevent premarital deviation (35\%), difficulty to get married later (28\%), less annoying to parents (13\%), less cost (15\%), and helping in childcare $(8 \%)$. This is in contrast with data from a study in Bangladesh [13] that showed that the main reasons for supported early marriage were less chance to go astray (24.5\%), very difficult to get married at later ages $(23.5 \%)$, and less troublesome to the parents $(22.9 \%)$.

The reason for not supporting early marriage, in this study were: harmful to mother $(26 \%)$, difficulty in childcare, discontinuation of education ( $18 \%$ each), hinders mother's ambition (15\%), mother's death due to childbirth $(13 \%)$, and causing anemia for the mother $(10 \%)$. Similar findings were reported from a study in Bangladesh [13]: leading to maternal and child health problems (37.7\%) and physical immaturity to have a child and difficulty in rearing an immature child (57.4\%) were the main reasons for not supporting early marriage. Another study in Pakistan [23] also showed the main reasons for not supporting early marriage were: harmful to mothers $(26 \%)$, difficulty in childcare, and discontinuation of education (18\% each).

Many studies [9,16,24-26] that investigated the determinants of early marriage showed that the most important determinants of early marriage showed that most important determinants were related to traditional, cultural lack of awareness of hazards of early marriage, and poverty. These studies emphasized on the importance of girls' education to prevent early marriage. Our study showed similar finding as we found that many factors were affecting women's attitude toward early marriage including age, poverty, residence, education, family income, tradition, and ignorance. However, in a multivariate analysis, significant factors for not supporting early marriage were higher education, believing early marriage is due to ignorance, or is more among relatives, or is causing health or social problems. These findings indicate the important role of education of either girls or their parents on facing the problem of early marriage.

\section{Strength and limitations of the study}

This study is a community-based study that included many women from rural and urban areas from six districts that represent the entire population in Sohag, one of the Upper Egypt governorates. So, it is possible to generalize our results to other governorates with similar characteristics. In addition, the prevalence, hazards, and attitude of women were obtained by self-reporting. However, there is some 
limitations of this study; mainly the recall bias of selfreported morbidity especially of elderly women. Some questions included medical terms such as uterine prolapse, gestational diabetes, preterm, LBW, etc., that need to be explained to some women to obtain a true response.

\section{CONCLUSION}

This study indicated that in spite of decreasing with age, the rate of early marriage is still high in Sohag governorate, Upper Egypt. The rate can be reduced by health education of parents about health and social hazards of early marriage on women and their children and by encouraging them to delay marriage until the legal age of marriage. Other important ways to decrease early marriage is to include the hazards of early marriage in the curriculum of preparatory and secondary schools and by encouraging girls to complete their secondary and university level which will delay marriage.

\section{Conflicts of interest}

No conflicts of interest.

\section{REFERENCES}

1. Jain S, Kurz K. New insights on preventing child marriage : a global analysis of factors and programs.: International Center for Research on Women (ICRW); United States Agency for International Development 2007. [cited 2017 March 2] Available from: http://lastradainternational.org/ lsidocs/icrw_child_marriage_0607.pdf .

2. Malé C, Wodon Q. Basic profile of child marriage in Egypt. Health, Nutrition And Population Knowledge Brief. World Bank. Washington, DC: World Bank; 2016.

3. Ministry of Health and Population [Egypt], El-Zanaty and Associates [Egypt], and ICF International. Egypt Demographic and Health Survey 2014. Cairo, Egypt and Rockville, Maryland, USA: Ministry of Health and Population and ICF International; 2015.

4. Le Strat Y, Dubertret C, Le Foll B. Child marriage in the United States and its association with mental health in women. Pediatrics 2011; 128:524-530.

5. Chaturvedi S, Kapil U, Bhanthi T, Gnanasekaran N, Pandey R. Nutritional status of married adolescent girls in rural Rajasthan. Indian J Pediatr 1994; 61:695-701.

6. Nour NM. Child marriage: a silent health and human rights issue. Rev Obstet Gynecol 2009; 2:51.

7. Kuhn L, Denny L, Pollack A, Lorincz A, Richart RM, Wright TC. Human papillomavirus DNA testing for cervical cancer screening in low-resource settings. J Natl Cancer Inst 2000; 92:818-825.
8. Rudäng R, Mellström D, Clark E, Ohlsson C, Lorentzon M. Advancing maternal age is associated with lower bone mineral density in young adult male offspring. Osteoporos Int 2012; 23:475-482.

9. Sarkar P. Determinants and effect of early marriage in Bangladesh, 2007. Res J Appl Sci 2009; 4:178184.

10. Santhya K, Ram U, Acharya R, Jejeebhoy SJ, Ram F, Singh A. Associations between early marriage and young women's marital and reproductive health outcomes: evidence from India. Int Perspect Sex Reprod Health 2010; 36:132-139.

11. Nour NM. Health consequences of child marriage in Africa. Emerg Infect Dis 2006; 12:1644-1649.

12. Nguyen MC, Wodon Q. Global trends in child marriage. Washington, DC: World Bank; 2012.

13. Rahman MM, Kabir M. Do adolescents support early marriage in Bangladesh? Evidence from study. J Nep Med Assoc 2005; 44:73-78.

14. Khalife N. How come you allow little girls to get married? Child marriage in Yemen. New York, NY: Human Rights Watch; 2011. p. 58.

15. UNICEF. Early marriage a harmful traditional practice: a statistical exploration 2005: UNICEF ; (cited 2017 July 20). Available from: https://www. unicef.org/publications/index_26024.html.

16. Chowdhury AH, Hoq M, Hossain ME, Khan MM. Factors affecting an age at first marriage among female adolescents in Bangladesh. Res Hum Soc Sci 2013; 3:131-139.

17. Walker JA, Mukisa S, Hashim $\mathrm{Y}$, Ismail $\mathrm{H}$. Mapping early marriage in West Africa: a scan of trends, interventions, what works, best practices and the way forward. Lagos: Ford Foundation. West Africa Office; 2013.

18. Palamuleni ME. Socioeconomic determinants of age at marriage in Malawi. Int J Soc Anthropol 2011; 3:224.

19. Bates LM, Maselko J, Schuler SR. Women's education and the timing of marriage and childbearing in the next generation: evidence from rural Bangladesh. Stud Fam Plann 2007; 38:101-112.

20. Westoff, CF. Trends in marriage and early childbearing in developing countries. DHS Comparative Reports No. 5. Calverton, Maryland: ORC Macro. [cited 2017 Aug 20]. Avialable from: https://www.dhsprogram. com/pubs/pdf/CR5/CR5.pdf

21. Sah N. How useful are the demographic surveys in explaining the determinants of early marriage of girls in the Terai of Nepal? J Pop Res 2008; 25:207-222. 
22. Abeynayake PB, Bomhoff EJ, Lee GH. Female age at first marriage and fertility levels: a comparison of developed and developing countries (October 19, 2012). Proceedings of 19th International Business Research Conference 2012. [cited 2017 Jun 20] Available at: https://ssrn.com/abstract $=2174737$.

23. Mukti IJ, Lutfunnahar B. Knowledge, approach and status of early marriage in Bangladesh. Science $2014 ; 2: 165-168$.

24. Ali A, Ibrahim I, Abdelgbar S, Elgessim M. Sociodemographic factors affecting child marriage in Sudan. J Women's Health Care 2014; 3:163.
25. Montazeri S, Gharacheh M, Mohammadi N, Alaghband Rad J, Eftekhar Ardabili H. Determinants of early marriage from married girls' perspectives in Iranian setting: a qualitative study. J Environ Public Health. 2016; 2016: 8615929.

26. Sumon MNK. Differentials and determinants of early marriage and child bearing: a study of the Northern Region of Bangladesh. Int J Sci Footpr 2014; 2:52-65. 